\title{
The Internet - an elitist luxury or the people's necessity?
}

\author{
C.E. Goble \\ (Derivco, South Africa) \\ Post Graduate Diploma in Information Management \\ RAU University \\ creaghg@microgaming.com
}

\section{Contents}

1. Introduction

2. What are the barriers of entry?

3. What are the recommendations to abolishing the barriers of entry?

4. What is the South African government doing?

5. Conclusion

6. References

\section{Introduction}

South Africa is a developing nation with many elements of a developed nation. It is unique in that for a period of 60 years legislation was in place that endorsed the concept of separate development. The result has skewed development growth along racial lines. South Africa's first democratic government has attempted to redress these inequalities by legislating to allow free and fair development for all. While to some extent this has been successful, the legacy of the past is still apparent today. In the global economy, South Africa is a relatively poor country with relatively under-developed skill sets and, by first-world standards, a poor telecommunications infrastructure.

In a developed economy, conditions for a competitive economic system exist. Conditions such as free entry and exit to markets, mobility of assets, many buyers and sellers and complete information are in place. In developing countries, however, these assumptions cannot be made and the conditions for free and fair competition do not exist. If accessing information is difficult, markets are underdeveloped, entry and exit from markets is complex and expensive, then information inequalities exist. These inequalities will exacerbate the existing differences between developing and developed countries.

'A fundamental paradox hangs like a shadow over telecommunications in Africa. The Internet is proclaimed to be a great leveler that will enable the continent to leapfrog over its own economic limitations; but at the same time, widespread use of the Internet in Africa is held back by a lack of technological infrastructure caused by those very limitations' Goldstuck (2000:48).

The Internet is a global resource, and is integral to the global information society (GIS). The Internet facilitates the sharing and dissemination of knowledge. From its very inception it has been a medium of knowledge exchange. Most developed countries have at the heart of their 
information technology policies the low cost and ease of access to this great pool of knowledge. The majority of South Africans, however, does not appear to have access to this resource and hence access to the GIS. Is the Internet then an elitist luxury or a people's necessity? To what extent are South Africans as a nation marginalized in the GIS because of this inequality? What are the barriers of entry to the majority of South Africans and what steps is the South African government taking to address this problem?

\section{What are the barriers of entry?}

South Africa has a significantly higher cost of entry into the GIS than countries in the first world. These barriers originate from bad regulatory practices and can be traced back to historical injustices associated with apartheid's separate development policies.

Regulation allowing Telkom a monopoly until the year 2003 has caused telecommunication costs to rise in a non-competitive market. Allied to this is high equipment and Internet service provider (ISP) costs. These factors have limited the entry into this market only to those who are able to afford it.

Compounding these barriers are the slow and unreliable connections made to ISPs due to South Africa's poor infrastructure, particularly in rural areas. Apartheid's separate development policies have left the majority of the population at a distinct disadvantage. The lack of training and the widespread use of English as a medium of communication prevent the majority of the South African people from participating in the GIS.

An underlying problem in South Africa is the low purchasing power parity (PPP) per capita when compared to the Organization for Economic Cooperation and Development (OCED) countries and the United States. This has hindered the majority of the population from participating in the GIS.

'In the end the most potent driver of skills transfer, as well as the economic benefits of ecommerce (sic), will be the wide accessibility and low cost of information and communication technology infrastructure' (Stravrou, May and Benjamin 2000).

\subsection{Telecommunication costs}

South Africa has only one authorized telecommunications company, Telkom. It has a monopoly and is the sole supplier of the country's telecommunication infrastructure. This monopoly has been enforced by a parliamentary act in 1997 that gave Telkom monopoly over South Africa's telecommunications infrastructure until 2002. The act also made provision for the monopoly to be extended to 2003, if Telkom can provide 2,8 million lines to areas that are not serviced. Since there is no competition, normal market effects prevalent in first-world countries such as the USA and the UK cannot play any role in bringing down the cost of telecommunication. This fundamental flaw in government policy has a ripple effect on all goods and services produced in this country as consumers absorb the non-competitive costs. In Portugal, for example, there are approximately 11 million users and 12 communication companies. In South Africa there are 30 million users and only one communication company.

According to The World Factbook (2001), which measures GDP per capita as purchasing power parity, the average South African has a purchasing power parity of $\$ 8,500$ per annum. The average American has a purchasing power parity of $\$ 36,200$ per annum and the average Britain has a purchasing power parity of $\$ 22,800$ per annum. The average world purchasing power parity is $\$ 7,200$ per annum.

South Africans therefore can be considered slightly better off than the average but significantly less well off than their European and American counterparts. This means that the average South 
African has proportionally less income to spend than the average European or American. In particular the income a South African can afford to spend on telecommunication is much less than what an American or Britain can spend. Of further significance is the relative cost of the telecommunication services of these countries.

In the US the cost of Broadband services from AT\&T is $\$ 200$ per installation and \$79 per month. This service allows the user $512 \mathrm{kbps}$ download speed and $128 \mathrm{kbps}$ upload speed. The equivalent bandwidth in South Africa would cost R1275 installation fee plus a monthly rental fee of R1500.

Using the Big Mac Index to determine purchasing parity the equivalent value in real U.S. dollar terms for South Africa is $\$ 841,50$ for installation and $\$ 990,00$ for monthly rental.

As a percentage of purchasing power parity (PPP) the rental represents in South African terms $127 \%$ of total income, while the equivalent service in the US is 3,1\% of total income. This is significant as the relative cost is 42 times more expensive in South Africa than in the US.

In the US, local calls are free and in the UK local calls are charged at a minimum of 2,5 pence per minute. Converting this to dollars using the Big Mac Index, the equivalent call will cost 3c. South African local calls costs 33 South African cents. If this is converted using the Big Mac Index the equivalent cost in the US dollars is 2 US cents a call.

This may not appear to be significant but if this is compared to the PPP index, the portion of cost per capita of a local call in the US is zero per cent, in the UK it is $0.00013 \%$ of purchasing power per anum and in South Africa it is $0.00027 \%$ of purchasing power per anum.

It is therefore clear that the cost of a local call in South Africa is significantly higher than in the US and the UK. The relative cost is double that of the UK and $270 \%$ more than the US. Telkom's pricing is therefore not competitive with the rest of the world and this is a very significant barrier of entry. If this market is opened to competition, the result will be lower telecommunication costs.

\subsection{ISP costs}

Internet access to home users is provided by local ISPs. The initial cost is the purchase of a subscription and then a monthly charge for that subscription. The additional cost of dial-up charge to the local ISP is currently 33c per minute during peak periods.

According to a survey conducted by Milne (2001) on the costs of Internet access in developing countries, it was found that for 20 hours of use per month the average PPP cost is $\$ 145,8$, compared to developed countries in which it is $\$ 44,1$ per month. The study found that less than $50 \%$ of this cost was the ISP cost. The balance was telecommunication cost.

The cost of connecting to an ISP is significantly higher in South Africa than in other countries. This represents 25\% of PPP per anum in South Africa while in the UK, a member of OCED, this represents only $0,2 \%$ of PPP per anum.

It is therefore relatively more affordable for someone in OCED countries to access the Internet than someone in South Africa. The portion of the population connected to the Internet will therefore be significantly lower in South Africa than in the OCED countries as the cost of entry is significantly higher. This is however only a single component of Internet access and should be considered with the other barriers to gain a complete picture of the extent of the problem.

\subsection{Equipment costs}

Access to Internet implies that the correct equipment is available and configured. The majority of computer hardware is imported into South Africa from abroad. 
AT\&T (2002) recommends the following as a market entry requirement for the Windows environment:

- PC with a Pentium 90 processor or faster

- Windows 95, 98, Me, NT 4.0 2000, or XP

- Microsoft Internet Explorer 5.0 or higher

- 32 MB RAM

- $20 \mathrm{MB}$ of unused hard disk space

- A 256-colour display

- A 14,4-kilobit-per-second (kbps) modem connected to an outside telephone line (28,8 kbps or higher recommended).

According to a study conducted by Männistö et al. (n.d) the initial set-up cost of hardware of this type may be as high as $\$ 1500,00$. While this may not appear to exclude many people from entering into the American market (only 3\% of PPP per anum), the cost of this hardware represents $12 \%$ of annual PPP per anum in South Africa. This raises the cost of entry into this medium too high for the average South African to afford.

In addition, the hardware must be configured and set up correctly, which requires some basic knowledge and training.

\subsection{Training and computer literacy}

The Internet is a complex network of Web sites and Web pages developed independently and without any pattern. Participation in the GIS requires the user to be able to use the Internet, and the various tools such as e-mail, as effectively and efficiently as possible. For the beginner the process of 'surfing the Web' is both daunting and difficult. Training in both the use of an Internet browser and the use of a PC is integral to being able to access the Internet. A basic knowledge of computers is required before a user is able to connect to the Internet and browse this resource.

According to a comparative study by the Worldbank (2001), the average illiteracy rate in South Africa in 1999 was 15\% of the total population. The same study shows that illiteracy in OCED countries is non-existent. To access the Internet a user must be literate. Although modern applications use picture icons and multimedia applications, information is still primarily text based and communication, especially e-mail, requires the user to read and write. In South Africa, $15 \%$ of the population will not be able to participate unassisted in the GIS because they are illiterate.

The number of people who are able to access the Internet in South Africa is further restricted because the user must have basic computer literacy skills. According to a study by Hodge and Miller in 1996, South Africa had a computer literacy percentage of 7,7\% of the population. While this may have changed to a degree, it nevertheless serves to highlight the problem that the majority of South Africans are unable to participate in the GIS because they do not possess sufficient skills to do so.

A comparison report published by the World Competitiveness Report (Institute for Management Development 1993) shows that South Africa rates behind India, the UK and the USA but is better off than Pakistan. While this report may be subjective, according to Hodge and Miller (1996) it gives a fair reflection of South Africa's position in relation to the rest of the world.

Table 1 Comparison of computer literacy rating (Institute for Management Development 1993)

\begin{tabular}{|l|l|}
\hline Country & Computer literacy rating (0-10) \\
\hline Singapore & 7,6 \\
\hline Japan & 7,3 \\
\hline &
\end{tabular}




\begin{tabular}{|l|l|} 
Chile & 5,9 \\
\hline USA & 5,7 \\
\hline Malaysia & 5,3 \\
\hline UK & 4,9 \\
\hline India & 3,4 \\
\hline South Africa & 3,1 \\
\hline Brazil & 3,1 \\
\hline Pakistan & 2,1 \\
\hline
\end{tabular}

The combination of adult illiteracy and computer illiteracy significantly raises the barriers of entry to the Internet and excludes the majority of the South African population. The relatively high adult illiteracy level implies that a large portion of the population must first learn to read and write before attempting to become computer literate. To address the inequality, a South African user must invest in both time and money. This in itself will pose a problem and hence excludes the vast majority of those that are illiterate. While training and literacy are important, according to Hodge and Miller (1996) the language problem poses an equally high barrier to entry into the GIS.

\subsection{Language}

The Internet was founded and based using the English language to send and receive information. English dominates the world of computing and information technology today. It is the most widely used computer language, being used by both developers and end-users alike. Most Web pages are written in English. Therefore, people who are unable to read, write or speak English are excluded from communicating in this medium.

In South Africa, the most commonly spoken language is Zulu spoken by $22,4 \%$ of the population followed by Xhosa 17,5\% then Afrikaans 15,1\% and finally English 9,1\% (Table 2). While all schools in South Africa require English to be taught as at least a second language, Hodge and Miller (1996) maintain that this is insufficient to meet the demands placed on acquiring and using knowledge in the GIS. They further state that sufficient understanding must be prevalent before being able to understand information resources fully.

Table 2 Distribution of home languages in South Africa (Central Statistical Service 2002)

\begin{tabular}{|l|l|}
\hline Home language & Percentage \\
\hline Afrikaans & 15,1 \\
\hline English & 9,1 \\
\hline Afrikaans/English & 0,2 \\
\hline isiNdebele & 1,5 \\
\hline Sepedi & 9,8 \\
\hline Sesotho & 6,9 \\
\hline siSwati & 2,6 \\
\hline Xitsonga & 4,2 \\
\hline Setswana & 7,2 \\
\hline Tshivenda & 1,7 \\
\hline isiXhosa & 7,5 \\
\hline isiZulu & 22,4 \\
\hline Other & 1,8 \\
\hline Total & $\mathbf{1 0 0 , 0}$ \\
\hline
\end{tabular}


The majority of Internet sites and information technology resources use English; there exists a natural language barrier to participating in the GIS for those who do not speak English and for those who have not yet mastered it as a second language.

\subsection{Speed}

Telkom supplies all South Africa's bandwidth with private companies leasing bandwidth from it. According to UUNET (2002), all bandwidth is carried by Telkom's ATM switched network. All ISPs therefore use Telkom's bandwidth as their backbone. The ISPs are governed and managed by a non-profit organization called the Internet Service Providers Association (ISPA). There are currently two international exchange points in South Africa, JINX (Johannesburg Internet Exchange) and Cape Town Internet Exchange (CINX). Both these peering points are controlled by ISPA. These peering points then join international points, for example UUNET connects to New York and Boston via dedicated leased lines.

The speed at which South Africa connects to peering points on other continents is dictated by the infrastructure Telkom has in place. According to a map published by www.ispmap.org.za, the available bandwidth to access international sites allocated to first tier ISPs was SAIX $42.5 \mathrm{Mb} / \mathrm{s}$, IS $166 \mathrm{Mb} / \mathrm{s}$ and UUNET $88 \mathrm{Mb} / \mathrm{s}$. According to a map published by WorldCom (2002), the line speeds connecting New York and London are $2500 \mathrm{Mb} / \mathrm{s}$. There is also not a single point of failure as, according to WorldCom, there are not only several lines connecting Europe with the USA but also several large companies including AT\&T and UUNET. More bandwidth and more lines are available in Europe and the USA than in South Africa. There is significantly more bandwidth available for international use in the USA and Europe than in South Africa.

The demand for international bandwidth is high as most sites are hosted in the USA and Europe. A home-user will typically connect to a local ISP and then be routed via this ISP to a Web site. Since most of these Web sites are hosted in the USA and Europe, connection speeds will be slow as international bandwidth is being used.

The baud rate of analogue telephone lines determines the bandwidth that the majority of South African Internet home-users have. It is seldom more than $56 \mathrm{~kb} / \mathrm{s}$ and in reality is between 19.6 and $28.8 \mathrm{~kb} / \mathrm{s}$. This is caused by the poor quality of telephone lines and the high cost of ISDN. European and American users have a higher quality connection because they have better quality telephone lines. These users also have access to higher connection speeds at lower cost. DSL and cable connections are the norm in Europe and America, while in South Africa analogue telephones are currently the only means available to connect to the Internet.

Jupiter MMXI's Online Market Landscape (2001) reports on Internet behaviour of over 5000 people every three months, covering Europe's three biggest markets: UK, France and Germany. The report shows that the home computer is still the most popular method of accessing the Internet. While European countries have good bandwidth available for home use at a very competitive rate, South Africans do not, hence the disparity between the number of European and South African users. This is highlighted by the fact that British Telecom (BT) in the UK is already offering users broadband connectivity options for home use at competitively low prices. In South Africa, Telkom is offering home users speeds of up to $128 \mathrm{kbs}$ using ISDN lines and modems but not yet broadband. The majority of South Africans cannot afford ISDN, as this is too expensive.

Because the connection speed to an ISP is, on average, much slower in South Africa than in developed countries, the time expended in accessing resources on the World-Wide Web is therefore much higher in South Africa than in Europe or America. More time is used to process this information in South Africa and hence the cost of this information is much greater. To compete globally on an equal level, the comparative times to access this information should be the same or very close. Because this inequality exists, the South African consumer or knowledge worker is disadvantaged and cannot compete fairly in the global market place. 


\section{What are the recommendations to abolishing the barriers of entry?}

To facilitate the smooth transition of South Africa into the GIS, careful attention must be paid by government to policies to lower the barriers of entry to the Internet. The steps that must be taken and policies to facilitate the transition include:

\subsection{Action plan}

According to Joslin (2001), there are several lessons that policy formulators must draw from the European Union experience. He says that a clear timetable and legal framework must exist so that government can implement policies that will direct societies' integration into the GIS. The Bangemann report of 1994 showed how European regulators clearly defined the GIS and set a clear timetable for its proposed implementation.

\subsection{Deregulation}

Competition causes the end-user to receive competitive prices based on the universal principles of supply and demand. The end of the Telkom monopoly will sound the beginning of universal access to the GIS in South Africa. The European Union, for example, asks that there be no limit on the number of licenses granted in the area of infrastructures and services. Licenses may only be refused if companies are deemed incompetent to provide this service. Because of the Telkom monopoly, SATRA (South African Telecommunications Regulatory Authority) is called on to determine whether Telkom pricing is fair or not. Market forces should be allowed to determine the price and this can only be achieved if open laissez-fair market conditions exist.

\subsection{Interconnection}

Conditions need to exists that will allow easy integration between the various service providers without prejudicing any new entrant. SATRA must be instrumental in assuring that new service providers can compete with existing ones. This will make allowances for free and fair competition. It will also lower prices and reduce costs of entry for both the end consumer and the service provider.

\subsection{Training}

Illiteracy and computer illiteracy must be reduced to enable participation of South Africans in the GIS. The reduction these illiteracies must occur at school level. Training must also include initiating both secondary and tertiary learners into the GIS by encouraging the use of online facilities and online resources. Government should actively encourage the use of on-line resources by providing all institutions with these facilities.

\subsection{Poverty}

This will always remain a problem but it can be alleviated if the South African workforce is equipped to compete with its global competitors. Currently the majority of the South African workforce lag behind because of the high barriers of entry into the GIS. 'The benefits of the Information Society will only be realized if all are able to participate in it' (Joslin 2001).

The South African government must provide low cost wireless technology so that the rural population will have access to the GIS and enable South Africa to compete globally.

\subsection{Leapfrog}

The lesson learnt by Europe and America must be studied and applied to South Africa. The costly and lengthily process of 'getting it right' can be avoided by formulating the correct policy framework and the best infrastructure. These lessons will enable South Africa to leapfrog the competition and employ the 'best of breeds' rules for integration into the GIS. 


\section{What is the South African government doing?}

\subsection{Action plan}

The South African government has gone a long way to formulating policies and action plans. These were modelled using the same processes used by the European parliament, in that experts submit green papers and these are used to formulate white papers. The white papers are then used to formulate policies. The new Telecommunications Act mandates the development of a universal service agency (USA), which will have as one of its primary responsibilities the achievement of universal access to the information infrastructure available in South Africa. The South African Acacia Advisory Group will collaborate with the USA to formulate and define policies, which will facilitate the transition of the South Africa society to the GIS.

\subsection{Deregulation}

Unfortunately Telkom still holds a monopoly in the telecommunication industry in South Africa and will, in all likelihood, maintain this stranglehold until 2003. While the privatization of Telkom is a step in the right direction, the dominance of this organization on the telecommunication industry severely hampers access to those who currently cannot afford this resource and therefore cannot participate in the GIS.

\subsection{Interconnection}

SATRA has been empowered to be the watchdog of the telecommunications industry. It is an independent body formed along the same lines as the Office for Telecommunications (OFTEL). OFTEL was established in the United Kingdom to deal with the liberalization of the telecommunications industry in that country. It was instrumental in deregulating that industry, thus ending the British Telecom monopoly in 1984. If SATRA is modeled on OFTEL, it should bode well for the future of the telecommunications industry in South Africa. If successful, SATRA should facilitate the deregulation of the telecommunications industry and provide the basis for free and fair competition in this industry. One of its most important tasks will be to ensure that, when this transition from monopoly to free market takes place, there are no barriers to new operators because of propriety telecommunication systems.

\subsection{Training}

Several training initiatives have been started at a grassroots level. Some of these are:

\section{SchoolNet South Africa}

This initiative aims to provide Internet and e-mail access to schools in South Africa. It also provides networked access to the various schools that belong to this organization.

\section{Curriculum development}

Allied to the development of a school network is the revision and adaptation of new curricula to best address traditional inequalities and prepare students for integration into the GIS. This project implements and evaluates the Technology Enhanced Learning Initiative (TELI), which emerged from a study undertaken by the South Africa Centre for Higher Education (SACHED) and SAIDE (South African Institute for Distance Education) for the Department of Education.

\section{Learning centre partnerships}

This project aims to bring basic skills and literacy to the job environment with buy-in from management and unions. The focus of these learning centres will be to improve adult literacy and 
computer literacy levels

\subsection{Poverty}

The fight against poverty is never an easy one but the following have been identified as key means to achieve this:

\section{SANGONet Technical Training Project}

SANGONet is a non-profit ISP involved in the dissemination of training on a local community level to encourage the use of the Internet and to promote the development of local content.

\section{Gauteng government}

The Gauteng government has undertaken to provide Internet access to all of its province's 1,5 million students by 2006. This is the first of this type of initiative in South Africa. To achieve this, the provincial government has earmarked 500 million rand over the next three years. The money set aside will also be used to send at least five teachers from each school to computertraining classes.

\section{Leylan Initiative}

The Leland Initiative is a five-year, \$15 million US government effort to extend full Internet connectivity to 20 or more African countries. This is intended to give access to these resources to those previously excluded from the Internet and thus from the GIS.

The South African government has empowered local governments to fight poverty and to provide access to basic commodities like electricity and water. It continues to attempt to improve the conditions under which the majority of South Africans live by inter alia providing rural telephone lines. Telkom has been tasked with this. One of the conditions of extending its sole telecommunications license was the provision of 2.3 million lines by 2003 to areas that are not serviced.

\subsection{Leapfrog}

The South African government has taken head of the lessons learnt by Europe and America. The degree to which the South African government has employed the best technologies and resources to develop the country and ultimately accelerate its integration into the GIS still needs to be assessed, but the foundations have been laid.

\section{Conclusion}

The Internet is and will remain an elitist luxury until the barriers of entry for developing countries are lowered or abolished. South Africans will continue to suffer the injustices of apartheid in the global economy and the GIS, as the relative cost of knowledge is much higher in South Africa than in developed countries. Perfect knowledge and access to this knowledge is a cornerstone of a free market economy. If this is extended to the global economy, South Africa is at a distinct disadvantage.

'Major elements of the country's IT infrastructure and educational system have effectively excluded the majority of the population from the economic and social benefits promised by the information society. While there is widespread recognition of this at the highest levels in the public and private sector, halting the trend towards exclusion and advancing the social and economic well-being of all sectors of the population through IT will require a very specific focus on information technology policy issues in the coming years' (Hodge and Miller 1996). 
While the South African government has taken steps to integrate society into the GIS by providing the framework to do so, significant barriers remain. The high entry cost into the GIS is still preventing the majority of the people of South Africa from participating in the GIS and from benefiting from it. Those who can afford to do so will always be in the minority until the costs and barriers are brought down.

The Internet is a luxury in South Africa that can only be afforded to those who have the disposable income to spend on the resource and the correct training to enable them to do so. The government has taken significant steps to attempt to make the Internet accessible to the majority of South Africans, but complete equality with developed countries is still some way off. Until this is addressed, the Internet will remain a luxury rather than a people's necessity.

\section{References}

AT\&T. 2002. AT\&T homepage. [Online]. Available WWW: http://www.att.com. (Accessed: 27 February 2002).

Bangemann, M. et al.1994.Recommendations to the European Council Europe and the global information society. [Online]. Available WWW:

http://europa.eu.int/ISPO/ida/text/english/bangeman.html. (Accessed: 25 February 2002).

Central Statistical Service. 2002. Homepage. [Online]. Available WWW:

http://www.statssa.gov.za. (Accessed 3 March 2002).

Goldstuck, A. 2000. Spreading the Web. Focus on Africa 11(4):48.

Hodge, J. and Miller, J. 1996. Information technology in South Africa. [Online]. Available WWW: http://www.sn.apc.org/nitf/untoc.htm. (Accessed: 1 March 2002).

Institute for Management Development. (n.d.) World Competitiveness Report.1993. [Online]. Available: http://www.sn.apc.org/nitf/unch4.htm. (Accessed: 2 March 2002).

Joslin, J. 2001. From monopoly to competition to convergence. [Online]. Available WWW: http://www.ecomm-debate.co.za/greenpaper/academics/joslin2.html. (Accessed: 26 February 2002).

Jupiter MMXI's Online Market Landscape. 2001.Internet access from home outstrips access from work. [Online]. Available WWW:

http://uk.jupitermmxi.com/xp/uk/press/releases/pr_091001.xml. (Accessed: 27 February 2002).

Männistö, K. et al. (n.d.). Internet and global information infrastructure in Africa. [Online]. Available WWW: http://www.itu.int/ITU-D/ict/papers/witwatersrand/tam tam.pdf (Accessed on 4 March 2002).

Milne, C. 2001.The costs of Internet access in developing countries. [Online]. Available WWW: http://www.itu.int/asean2001/documents/pdf/Document-16.pdf (Accessed: 3 March 2002).

Stravrou, A. May, J. and Benjamin, P. 2000. E-commerce and poverty alleviation in South Africa: an input paper to the government green paper. [Online]. Available WWW: http://www.ecomm-debate.co.za/greenpaper/academics/stravrou.html. (Accessed 3 March 2002).

The Economist. 2001. Big Mac currencies. [Online]. Available WWW: http://wwwpersonal.umich.edu/ kathrynd/bigmacindex2001.pdf. (Accessed 1 March 2002).

The World Factbook. 2001. [Online]. Available WWW: http://www.bartleybooks.com. 
(Accessed: 1 March 2002).

Topological map of Southern African Internet access providers. 2001. [Online]. Available: http://www.ispmap.org.za/. (Accessed 1 March 2002).

UUNET. 2002. Homepage. [Online]. Available WWW: http://www.uunet.com. (Accessed 10 March 2002).

WorldBank. 2001. World development indicators database. [Online]. Available WWW: http://www.worldbank.org/data/databytopic/ILIT.pdf. (Accessed 3 March 2002).

WorldCom. 2002. Maps, North America. [Online]. Available WWW:

http://www1.worldcom.com/global/about/network/maps/northam/. (Accessed 27 February 2002).

\section{Disclaimer}

Articles published in SAJIM are the opinions of the authors and do not necessarily reflect the opinion of the Editor, Board, Publisher, Webmaster or the Rand Afrikaans University. The user hereby waives any claim he/she/they may have or acquire against the publisher, its suppliers, licensees and sub licensees and indemnifies all said persons from any claims, lawsuits, proceedings, costs, special, incidental, consequential or indirect damages, including damages for loss of profits, loss of business or downtime arising out of or relating to the user's use of the Website. 